\title{
Assignment of Purchases to Suppliers through a Reverse Auction with Multiple Offers of Lots
}

\author{
David de la Fuente, Jesús Lozano, Nazario García, Alberto Gómez, Isabel Fernández, and Borja Ponte
}

\begin{abstract}
The problem of assigning purchases among multiple offers lots is easy and quick to resolve since its underlying complexity is related to the elected ordination algorithm. We have chosen a programming language which implements the algorithm "merge sort" and whose behavior in the worst case scenario is $O(N \log N)$. This algorithm is already implemented in sophisticated languages such as Perl, Phyton or Java.
\end{abstract}

Index Terms - Lots, reverse auction, sorting method.

\section{INTRODUCTION}

Reverse auction is a tool used in the business contracting in which, in contrast to the forward, common or ordinary auction, the seller and buyer role is inverted. In a forward auction the buyers compete to obtain a good or service that a seller puts on sale, being the bidder the one who pays more for the good or service. In a reverse auction, the sellers compete to obtain the sale of goods or services from a buyer and the winner is the seller who offers the product that the buyer needs at the cheapest price.

In a forward auction, the seller offers a number of units of products and waits for sale offers what gradually increase the price. In the reverse auction, the buyer announces that he is demanding a number of units of a product and waits for sale offers, and those that satisfy the necessity of the buyer at the minimum possible price are selected.

The reverse auction searches a transaction mechanism when there are enough offers either for goods or services, and the demand shows the necessities and let the offer complete in order to satisfy them.

When the auction process is done through Internet, we speak about e-auction. In fact, when we refer to the reverse e-auction, we are talking about a dynamic process of negotiating online prices among preselected suppliers in order to achieve a business. It is a system in which the personal relationship with the client to speak about a negotiation through Internet disappears. Against the traditional system of negotiating, in the reverse e-auction, the seller who offers the lowest price is the one who wins. This process features some advantages and disadvantages. We can point out the following advantages: the increase of potential

Manuscript received September 3, 2013; revised November 9, 2013. This work has been supported by the Government of the Principality of Asturias, through Council of Economy and Employment. (Project Reference: SV-PA-13-ECOEMP-74)

The authors are with the Department of Business Administration, Polytechnic School of Engineering (University of Oviedo), Campus de Viesques s/n, CP 33204, Gijón (Asturias), Spain (e-mail: david@uniovi.es, lozano@uniovi.es, ngarciaf@uniovi.es, albertogomez@uniovi.es, ifq@uniovi.es, uo183377@uniovi.es). providers, since the geographical distances do not exist anymore, generation of savings of costs of purchases, non-personalization of the offer avoiding possible favour treatment between the seller and buyer, and reduction of mistakes. On the other hand, the disadvantages are some aspects that change the traditional scheme of negotiating (conditions of contract imposed by the client, limited time available for the provider, circumscription almost exclusive to the price) and some practices which are considered unfair (introduction of "ghost offers" by the client in order to decrease the prices, the buyer calls the seller in order to put pressure in order to reduce the prices, illegal agreements among providers, conditions of adjudication and unclear, incorrect or incomplete specifications of the product).

The fact that a company can state the desired transaction with the desired price and also that the offer competes so the transaction can be done, and besides, that it can be done through Internet can alter the way of competing in many sectors.

In the field B2C (Business to Consumer), the reverse auctions are successful in travels, hotels, cars, etc., however, they fail in other things such as the market basket or petrol, among others. But in the field B2B (Business to Business) it does not have to be that way and the purchase function can be altered with this tool.

Types of reverse auction: Taking into account if the information that is provided to the participant seller or not, we can talk about open reverse auctions (they let see the evolution of the values) and position reverse auctions (they only show the position of our offer)

According to the format of the auction, we can differentiate between auctions in which it is only allowed to present an offer which is higher than the existent one or auctions in which it is allowed to offer when introducing higher percentages over the existent one. Taking into account the sale criteria, there are auctions (the most usual ones) in which the lowest price wins; another kind in which the introduced offers can win although they are not the lowest one in price, because other corrective factors of the price are requested; and finally, the model, commonly called double auction for some purchase lots, in which we have a double process: first of all, the lots to be bought in a unit way are auctioned and, later, an aggregation of all, taking as a starting price the lowest one in the previous operation.

Reverse auction process: In a reverse auction process, we can differentiate the following phases:

1) Preparation of the lots subjected to auction: the client requests information to the usual suppliers of a complete dossier of the products provided by them (price, delivery conditions, and technical specifications) and he makes 
the lots which are subjected to value.

2) Pre-selection of participants (known suppliers, approved suppliers, suppliers provided by the auction organizer or new suppliers).

3) Request of information to every supplier related to his identification, economical and financial, commercial, productive and quality aspects.

4) Request of prices to the suppliers for the references to be valued. A breakdown can be requested, differentiating the row material cost, transformation cost, transport cost, mark-up and final price. In order to exercise this bid, the bidders will have received an adequate and enough information about the features of the product so it can be quoted in a proper way.

5) They communicate the information about the auction related to date, purchase portal, conditions, contact telephones, etc. and name and password are submitted so they can participate.

6) Carrying out of the auction and sale.

In this work in which we present the lots offered by the seller, you can see a number of units lower than the demanded ones. This condition is acceptable if we understand that the practice of the inverse auction looks for, among other goals, the decrease of the time of management and stock, and, therefore, if the buyer needs "x" units in a determined period of time, and he did not find in the market the only supplier who could deliver them in that time, there is always the option of meeting the necessity turning to many suppliers who would provide partial and lower amounts than the total, so the goal of meeting the total necessity " $x$ " in the period established by the buyer will be met with the sum of deliveries done by the different suppliers selected within that period of delivery.

The list of suppliers can be closed in order to resolve the problem of supervision of the quality; or open to new companies. The decision criteria will be based in the minimum unit price, and since there are multiple offers, that will lead us to a problem of ordination from lowest to highest unit price of the lots.

On the other hand, and given what has been previously exposed, for the work that we present, we admit the divisibility of the offered lots and the possibility of buying always the exact number of demanded units. Otherwise, the problem becomes more complex (NB-complete) It is known as knapsack problem [1]-[3]. In any case, it is possible to optimize a set of offers. There is a branch from the game theory which studies the efficiency of the auctions in its different modalities [4].

\section{STATE OF THE ART}

In terms of theoretical research, the problem of the purchase reverse auction has been treated from different points of view: about the controversy of its application [5], [6], as strategic and operative implication [7], the problem of auctioning purchase lots or packets [8], the impacts on the price and possibility of opportunism from the suppliers with experience in laboratory [9], or the diffusion of such practices [10]. The focus that we propose is to exemplify the simplicity of implantation of the system.

\section{PROPOSED AlgorithM}

The resolution of the problem is simple and is based of three phases. In the first one, the offers will be received, and can be made public (what it seems that it improves the price) or not (when the quality is endangered of for high sums [11]), during a period of time and the average unit prices implicit in each offered lot will be calculated.

Typically, the demand will take the form of a web page in html language, where the specifications are advertised and with a link to a program CGI where the bidders can introduce their offers and the program writes the data in a unique file (the index-counter must be saved in another protected file against concurrences).

In the second phase, this file will be arranged according to the unit price, what represents the most critical phase in a computational way, but the current hardware processes in little time [12].

Finally, a selection phase is needed in which the demands and the offers are assigned until a rest lower that a lot is calculated to sell to the next bidder. This process can be done with total security since the ordination criteria has been the average unit price. In a practical implementation it only remains that after supervision in search of anomalies [1], [13], the orders by the suppliers are grouped and these are sent per mail or through another service TCP/IP.

\section{Structure OF DATA}

Because of simplicity with a view to the processes of reverse ordination, each offer of a Lot is saved as a line of a matrix of two dimensions. The first field or column to be introduced will be a number-index that is going to be assigned according to the order of arrival, so it can break a draw in favour of the natural order of arrival of the offer, giving priority to the oldest offers. The second field will be the identifier of the bidder for mere interest. The third field will be the size of the Lot for which the offer is done. The fourth and last field will be the average unit done. The fourth and last field will be the average unit price of the Lot, which can be calculated when the offer arrives and can be invariant during the process.

\section{CODE OF EXAMPLE}

The programming language that we have chosen has been the Perl, due to its simplicity and power. It is freely available for all operative systems [14]. In this language, the reception of offers of lot sale is simulated and then it proceeds with its ordination (Table I and Table II).

In these three simulations we have used random number of a queue from a normal one what at the same time it makes use of the algorithm random 48() uniform[UdO1] . This system has been chosen because it is the one that produces a lower number of prices or amounts of offers candidates exceptionally high or low.

As it was predictable for times of 2, 0.5 y 0.01 seconds of creation of offers, we obtain the best auction prices when the time and the number of received offers is higher. 
TABLE I: CODE

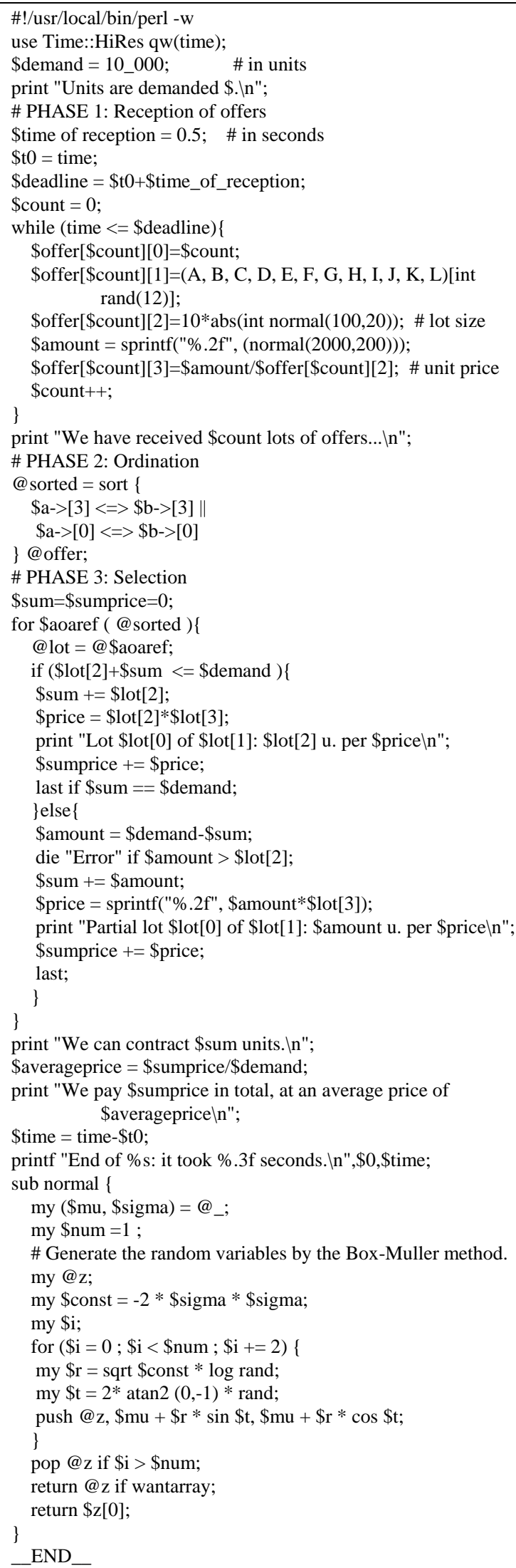

\section{ALGORITHM SPEED}

The algorithm speed is an notable aspect which facilitates the implantation Although this can vary very much in related terms depending on the used language and architecture, in absolute terms it does not suppose a bottle neck for the decision of launching purchase orders The calculus of the ordination an only suppose just few seconds in relation to a high volume of offers and periods of reception of offers which are measured in days.

\section{TABLE II: OUTPUT}

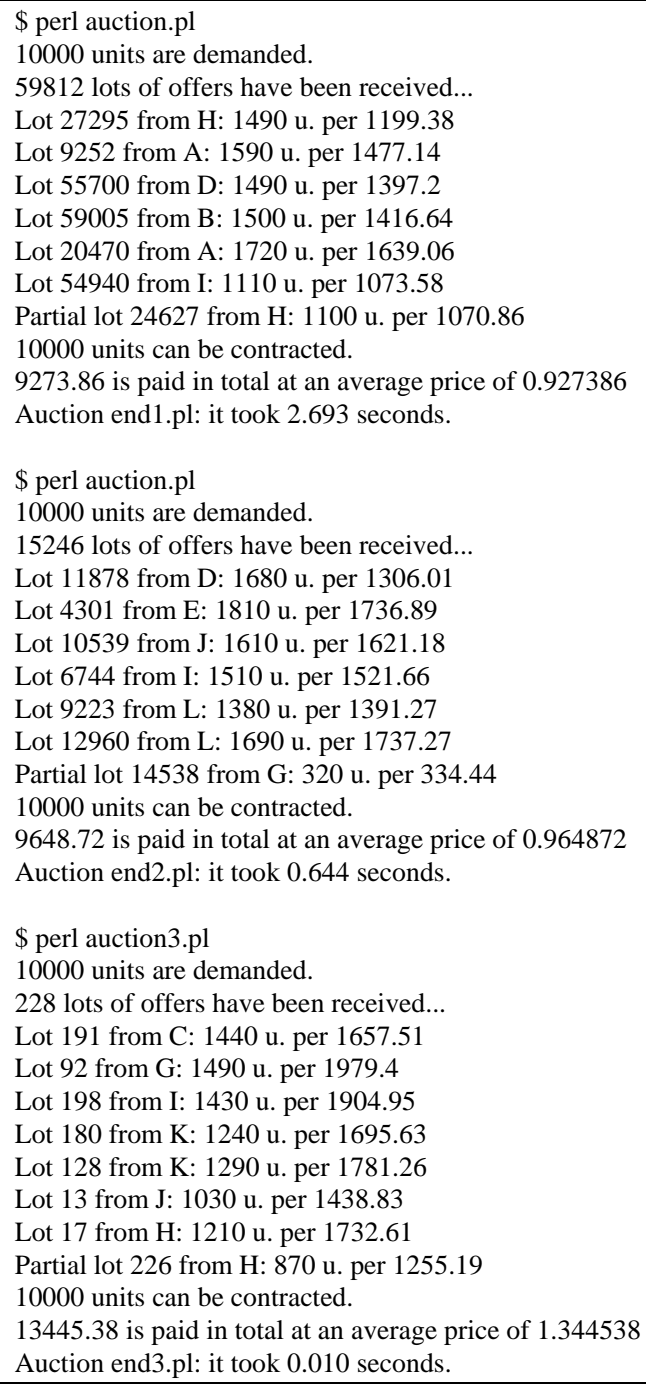

\section{VARIATIONS}

It is possible to implement a system of forward auction to clients in an analogue way to the one here presented to the suppliers. Basically, it would be to change the code "sort..." to "reverse sort..." and make it in two steps, since our preference in case of draw is the one of the oldest lot, this criteria should not change.

\section{IMPLICIT ASSUMPTIONS}

It is very common to maintain closed lists of suppliers, what is motivated for knowing contractually a prior the conditions of devolution of materials, payments, etc. However, this practice limits the competence among suppliers that downwards put pressure on the price of purchase. The same happens with the auctions with "closed envelope" Such measurements are taken when the quality of the offered product is endangered and they can reduce considerably the benefit of applying the reverse auction to the 
suppliers.

In the purchase departments they identify the different products that the company usually buys and the identify suppliers according to these products. These suppliers can have suffered a process of initial homologation, which consists of a valuation of their technical capacity, productive organisation, technological levels, staff capacity, evaluation of their quality system, economic solvency, etc. If they pass a minimum valuation or evaluation $(75 \%$ is usually considered in percentage terms), they become part of the lust of homologated suppliers for this product.

Subsequently, once a supplier has a commercial relationship with the company, that means, we have made a purchase order acquiring some amount of that product that we need, a evaluation of its behaviour is done and, at least, it has to meet three aspects: behaviour in prices (comparing it with other suppliers who can serve that product), behaviour according to the quality (Percentage of units of products that he has delivered according to the demanded one, that means, that there is no rejection, and behaviour according to the fulfilment of deliveries (percentage of orders which meet the agreed date of delivery and there has not been any rejection).

In short, there are occasions in which, due to problems of quality, continuity in the relationships of simply because the economic benefit of applying auctions is very low, closed lists of "homologated" suppliers are created and the presented possibility is limited. However, we must remember that with the opening of markets, the possibilities of search of competitive suppliers gets wider and the use of reverse auctions makes sense again.

\section{Multiple PRODUCTS}

The proposed algorithm is valid for multiple products taking separate instances for each product. This implies a great simplicity and computing scalability. It is possible to give out the job among multiple servers, for example, according to the kind of products or raw materials.

\section{CRITICS TO THE SYSTEM}

It is necessary that the demanded product or raw material is homogeneous among suppliers. This restriction can limit the application field. However, the most abstract critics to the system are that the auction system "destroys" the relationships with the suppliers. But if we consider that the product or raw material is enough homogeneous, there are no many reasons to maintain privileged relationships with some suppliers and to commit to the cost of opportunity of losing the competence among them which reduces the cost of the purchases (it can be 15-20\% [9]). We can also say that when this kind of system is implanted, with a standardised advertisement and periods of time, the suppliers can plan better at a longer term their production than with a system of greater specific and more sporadic orders. Additionally, the system simplifies the entry of new suppliers that may need to have the provisioning logistics more updated.

\section{CONCLUSIONS}

Implementing a system of reverse auction to select and manage the purchases to the suppliers is possible and simple. The limitations of a system of this kind are those related with the quality supervision and control. The open possibilities with this kind of downward auction are related to the advertisement or not of the offers between the competitive suppliers and the periods in which they receive offers. In fact, the proposed system of purchase management of lots optimizes the average price, being the result independent from a determined politics of concentration or diversification of purchase.

\section{REFERENCES}

[1] D. E. Knuth, The Art of Computer Programming, Volume 3: Sorting and Searching, Second Edition, Section 5.2.4: Sorting by Merging, Addison-Wesley, 1998, pp 158-168.

[2] S. Martello and P. Toth, Knapsack Problems: Algorithms and Computer Implementations, John Wiley and Sons, 1990.

[3] H. Kellerer, U. Pferschy, and D. Pisinger, Knapsack Problems, Springer Verlag, 2005.

[4] Y. Shoham and K. L. Brown, Multiagent Systems: Algorithmic Game-Theoretic and Logical Foundations, Cambridge University Press, New York, 2009

[5] P. Klemperer, Auctions: Theory and Practice, Princeton University Press, 2004

[6] S. Kumar and M. Maher, "Are the temptations of online reverse auctions appropriate for your business?" Supply Chain Management: An International Journal, vol. 13, no. 4, pp. 304-316, 2008.

[7] S. D. Jap, "Online reverse auctions: issues, themes, and prospects for the future," Journal of the Academy of Marketing Science, vol. 30, no. 4, pp. 506-525, 2002.

[8] T. Schhoeenherr and V. A. Mabert, "The use of bundling in B2B online reverse auctions," Journal of Operations Management, vol. 26, pp. $81-95,2008$.

[9] C. R. Carter and C. K. Stevens, "Electronic reverse auction configuration and its impact on buyer price and suppliers perceptions of opportunism: A laboratory experiment," Journal of Operations Management, vol. 25, pp. 1035-1054, 2007.

[10] T. Schoenherr, "Diffusion of online reverse auctions for B2B procurement: an exploratory study," International Journal of Operations and Production Management, vol. 28, no. 3, pp. 259-278, 2008.

[11] R. Katkar and D. L. Reiley. (2001). Public Versus Secret Reserve Prices in eBay Auctions: Results from a Pokémon Field Experiment (NBER Working Paper No. 8183). Department of Computer Science, Princeton University. [Online]. Available: http://www.cs.princeton.edu/courses/archive/spr09/cos444/papers/LR-Katkar-Public00.pdf

[12] Perl Programming Documentation. [Online]. Available: http://perldoc.perl.org/

[13] O. Ashenfelter and D. Genesove, "Testing for price anomalies in real-estate auctions," American Economic Review, vol. 82, no. 2, pp.501-502, 1992.

[14] Comprehensive Perl Archive Network. [Online]. Available: http://www.cpan.org

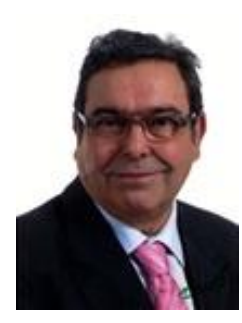

David de la Fuente is a full professor, Operations Management \& Management Science. Ph.D Management Science (1987, Universidad de Oviedo) (Extr. Thesis Award). Vice Dean - Industrial Engineering School, University of Oviedo, Spain, (1987-1991). Invited professor at several Latin-American Universities (in Bolivia, Argentina, Cuba, El Salvador etc.) Member of the Internationa Scientific Committee of 30 Technical Conferences. Director of several research projects (European national and regional), and contracts with companies. 20 Papers in international journals indexed by JCR and SJR. Member of POMS, EurOMA and INFORMS, etc. 


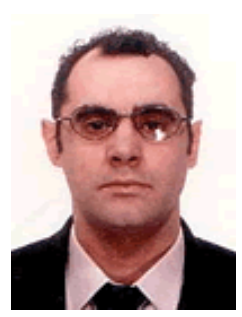

Jesús Lozano was born in Gijón, Spain, 1966, has a degree in Economics and Management by the University of Oviedo, a master in Accountant Audit and a doctorate in Business Administration. Actually is a professor of Business Administration in the University of Oviedo, Spain.

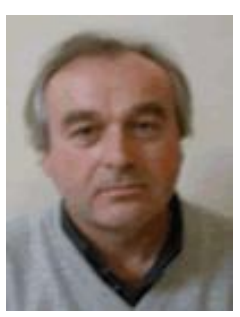

Nazario García is Ph.D doctor and MBA. He is a senior lecturer and researcher of the University of Oviedo (Spain) since 1998, affiliated to the Business Administration and Accounting Department. Former Purchasing manager at a military company, where he worked during 24 years. Also in charge of Supplier evaluation and internal audits. Counselor in rural hotel and industrial waste treatment plant implementation. Several national and international publications. Participation in six research projects and national and international scientific conferences. Visiting lecturer at the University of El Salvador and La Habana (Cuba). Seminars and courses on Marketing, Logistics, Purchasing, Production and Quality. Currently he is Secretary of Asturian Logistics Foundation.

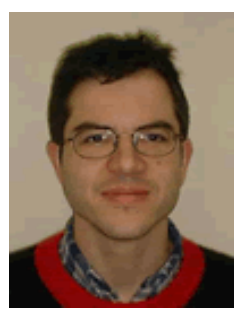

Alberto Gómez works for the Department of Business Administration and Accountability, at the School of Industrial Engineering of The University of Oviedo, Spain. His teaching and research initiatives focus on the areas of Production Management, Applied Artificial

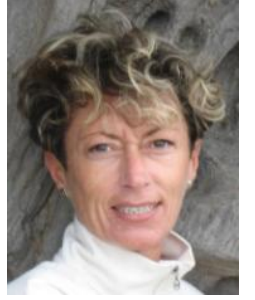

Isabel Fernández is Ph.D doctor and MBA. She is a senior lecturer and researcher of the University of Oviedo (Spain) since 1997, affiliated to the Business Administration and Accounting Department. In 2002 she enjoyed a 1 year and 9 months permission leave in the University of Vaasa (Finland), in the Industrial Management Department. Visiting lecturer of International Management Program in the IESEG in France. Previously she worked in Public sector (1 year), Private sector (2,5 years) and in a Polytechnic School (1 year). Areas of her interest are Logistics (more specifically Reverse Logistics), Production Organization, Costs analysis and Forecasting. Author of several publications in different national and international journals and chapters of books. Attendance to more than 80 national and international scientific conferences. Participation in several research projects. Member of the directors board of the International Society For Productivity And Quality Research.

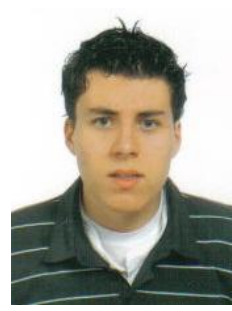

Borja Ponte is a Ph.D student at the Department of Business Administration of the University of Oviedo. His Master's Thesis "The Bullwhip Effect in Supply Chains: An Approach based on Artificial Intelligence Techniques", qualified with honors, represents his introduction into the world of research, trying to combine the fields of Logistics and Multiagent Systems. He has presented papers at two internationa conferences, and he has participated in the work presented in two others. 